\title{
SOCIO-DEMOGRAPHIC RISK FACTORS OF SEVERE MALNUTRITION FOR CHILDREN AGED UNDER FIVE INVOLVING VARIOUS BIRTH COHORTS IN BANGLADESH
}

\author{
Mohammad Rocky Khan Chowdhury \\ Research fellow, Department of Population Science and Human Resource \\ Development, University of Rajshahi, Bangladesh; Commonwealth PhD Scholar, The \\ Graduate School, University of West London, United Kingdom;\& Lecturer, \\ Department of Public Health, First Capital University of Bangladesh \\ Email: rurocky84@gmail.com \\ Hafiz T.A. Khan \\ Professor, Public Health \& Statistics, The Graduate School, University of West \\ London. London, United Kingdom \\ Email: hafiz.khan@uwl.ac.uk \\ Md. Nazrul Islam Mondal \\ Professor, Department of Population Science and Human Resource Development, \\ University of Rajshahi, Bangladesh \\ Email: nazrulupm@gmail.com

\section{Russell Kabir} \\ Senior Lecturer, School of Allied Health, Faculty of Health, Education, Medicine and \\ Social Care, Anglia Ruskin University, Chelmsford, Essex, United Kingdom \\ Email: russell.kabir@anglia.ac.uk
}

\section{Keywords}

Socio-demographic, under-five child and severe malnutrition 


\section{Summary}

Tackling malnutrition is a major global health priority for a developing country like Bangladesh. This paper explores the epidemiological differences between only one form and multiple forms of severe malnutrition among children in Bangladesh aged under-five years. Also, it identifies important factors that are associated with both these forms. Data were extracted from the Bangladesh Demographic Health Surveys of 2007, 2011 and 2014. The outcome measures included only one form and multiple forms of severe malnutrition in children aged under-five years. A Chi-square test was performed to find the association of outcome variables with selected socio-demographic factors and logistic regression models helped identify the risk factors. A total of 19,874 children aged under-five years were included in the current analysis. The overall proportion with one form of severe child malnutrition was approximately $11.53 \%$ and with multiple forms was $7.60 \%$. The analysis showed that age, mothers' education, fathers' occupation, mothers' currently working, watching television, source of water, solid waste used in cooking, intimate partner violence (IPV), wealth index, place of residence and birth cohort were significant factors for both one and multiple forms of severe child malnutrition. Those children that had a non-educated mother and came from a poor socioeconomic class were associated with a high risk of severe malnutrition. Where a father had an occupation service, any children were at less risk of multiple forms of severe malnutrition. The proportion of severe malnutrition in children aged under-five years with one form and multiple forms was shown to be high in Bangladesh with the risk identified using selected variables. Prevention of malnutrition in Bangladesh should, therefore, be seen as a significant public health issue and given top priority. 


\section{Introduction}

Malnutrition among children aged under-five years is one of the major health and wellbeing problems currently affecting Bangladesh (NIPORT, 2016). It comprises three fundamental indicators of insufficiency, such as stunting (short stature for age), wasting (dangerously thin) and underweight (being underweight for one's age) (Chowdhury et al., 2016). Children with malnutrition face both short and long-term adverse health consequences that are associated with reduced cognitive development and increased risk of death due to all causes including diarrhoea, pneumonia, and measles (Black et al., 2013). More drastically, the degree of cognitive impairment is directly related to the severity of stunting and mental impairment caused by iodine deficiency is permanent and directly linked to productivity loss. Extreme wasting is responsible for a high mortality rate and being severely underweight is a form of chronic malnutrition, often referred to as hidden hunger, that has a significant impact on health, development, and productivity over the lifespan. Besides, chronic malnutrition has been associated with impaired thymic development that results in decreased peripheral lymphocyte count that can lead to increased susceptibility to infections. Severe malnutrition also impairs the innate host defence mechanism, further diminishing the body's immune system (Khattak et al., 2017). Several studies identified only one adverse outcome of malnutrition among children (Islam et al., 2019; Sultana et al., 2019; Chowdhury et al., 2016; Islam et al., 2013) so the consequences of severe malnutrition still underreported. There is a lack of research on the health consequences for children with multiple adverse nutritional outcomes. The health status of children aged under-five years with the state of concurrence might be critical. Evidence indicates that children who are concurrently wasted, stunted and underweight experience an excessive mortality with that higher still among children in a severe state of concurrence (Myatt et al., 2018). 
About 255 million children worldwide aged under-five years are suffering from malnutrition (Tebeje et al., 2017). Of these, an estimated 52 million (around 8\%) are wasted; 165 million (around 26\%) are stunted, and 101 million (around 16\%) are underweight (Chowdhury et al., 2016). Approximately half of all deaths of children aged under-five years are attributable to malnutrition (UNICEF, 2015). These figures demonstrate that there is an avertable loss of many young lives. South Asia is home to approximately $38.9 \%$ of the world's stunted children and $50 \%$ of wasted children, giving it the highest burden of the regions (Development Initiatives, 2018). A total of 124 countries out of 141 are struggling with multiple forms of malnutrition, with $29 \%$ (41 countries) of these having high levels of all three forms of malnutrition. It is estimated that around $3.62 \%$ of children aged under-five are both stunted and wasted while globally, $1.87 \%$ of such children experience both stunting and being overweight (Development Initiatives, 2018). Bangladesh is considered to be in a catastrophic situation due to adverse nutritional outcomes that reveal more than $35 \%$ of children are under attack by one or more forms of malnutrition (Chowdhury et al., 2016). More than $50 \%$ of under-five child deaths are attributable to malnutrition (Chowdhury et al., 2016). Although Bangladesh has made good progress in the last two decades to achieve the Millennium Development Goals, MDG-1 (eradication of extreme poverty and hunger); MDG-4 (child mortality). Moreover, currently focusing on the Sustainable Development Goal, SDG-2 (ending hunger, achieving food security, improving nutrition, and promoting sustainable agriculture), much more needs to be done (Bhutta, 2017; Chowdhury et al., 2016). Unfortunately, Bangladesh has not been very prosperous in addressing the problem of child malnutrition. Severe malnutrition increased from $16 \%$ in 2011 to $18 \%$ in 2013 which may be due to an increasing rate of malnutrition among mothers, poor socioeconomic status of parents, relatively low rate of fully breastfeeding babies, and food insecurity (Islam \& Biswas, 2015). Besides, more than $30 \%$ of children aged under-five are suffering multiple forms of 
malnutrition (NIPORT, 2016). There was a marked decline in malnutrition rates in Bangladesh after the 1990s, but the current rate is one of the highest in the world.

The aetiology of malnutrition, more particularly, severe malnutrition is still an issue of deliberation (Hossain \& Khan, 2018). The present study is mainly based on two facts, one is severe child malnutrition, and another is the classification of cases in terms of one form and multiple forms. Several epidemiological studies suggest that malnutrition involves not only lack of nutrients, but also other risk factors such as socio-demographic, household possession, geographical location, lack of access to healthcare and poverty and so on (Walson \& Berkley, 2018; Madhusudhan et al., 2017; Chowdhury et al., 2016; Aguayo et al., 2015; Rahman et al., 2012; Kandala et al., 2011; Pongou et al., 2006; Smith et al., 2005). These studies addressed the socio-demographic risk factors only in case of single malnutrition indicators separately, that is, stunting, wasting and underweight. Identifying the socio-demographic risk factors of severe child malnutrition has been insufficiently addressed (Islam et al.,2019; Madhusudhan et al., 2017; Pravana et al., 2017; Talukder, 2017). These studies also highlighted the sociodemographic risk factors for an only single severe case. However, studies link with only one form, which includes the combination of severe stunting, wasting and underweight, and multiple forms were not significantly addressed. Evidence suggests that children with severe wasting are also severely stunted (Ngari et al., 2019). Many studies have already been conducted on identifying the risk factors for malnutrition affecting children aged under-five in Bangladesh (Islam et al., 2019; Talukder, 2017; Chowdhury et al., 2016; Rahman et al., 2012). However, such studies do not disentangle the complex mechanisms underlying malnutrition, such as risk factors associated with a single case and multiple cases. The number of risk factors for malnutrition among children with only one case would likely be more distinctive than those among children with multiple cases due to the multifaceted outcomes of each malnutrition indicator. Understanding the severe nature of malnutrition that claimed nine times higher death 
toll rates than healthy children, demands a comprehensive study. the present study has the following objectives:

(i) to observe the epidemiological difference in terms of prevalence and sociodemographic determinants between one form and multiple forms of severe malnutrition among children in Bangladesh aged under-five years;

(ii) to identify the socio-demographic risk factors that are most significantly associated with one form and multiple forms of severe child malnutrition.

\section{Methods}

\section{Data source}

Three waves of data from the Bangladesh Demographic Health Surveys (BDHSs) of 2007, 2011 and 2014 were used in this study. Details of the survey questionnaire, sample design, data collection procedure and all other issues are discussed elsewhere (NIPORT, 2009, 2013, 2016). The BDHS samples were drawn from Bangladeshi adults residing in non-institutional dwellings. Each wave of these surveys used multistage stratified sampling techniques of households with enumeration areas (clusters) taken from the 2001 and 2011 censuses compiled by the Bangladesh Bureau of Statistics and used as the primary sampling units (PSUs) (NIPORT, 2009, 2013, 2016). At the first stage of sampling, 600 PSUs were selected with probability proportional to their size. The resulting lists of households were used as sampling frames for the second stage of sampling that involved 30 households selected from each PSU using an equal probability systematic sampling technique. 
All children listed in the survey were born in January 2002 or later and were aged underfive years, so all of them were eligible for height and weight measurements. The United Nations Children Fund provided logistical support. Implausibility was defined and based on World Health Organization (WHO) 2006 standards flag limits of z-score: stunting: <-6 or >6; wasting: $<-5$ or $>5$; and underweight: $<-6$ or $>5$. A total of 20,387 children aged under-five in the BDHS sample households were eligible for anthropometric measurements. However, out of this total, only anthropometric and socio-demographic data available for 19,874 children were considered complete and credible (Figure 1). In the combined dataset $(n=19,874)$ the contribution of the three waves of surveys was $27 \%, 38 \%$ and $35 \%$ respectively. These surveys were conducted to collect data on health and nutritional indicators to monitor a wide range of the population. Trained staff collected detailed information on the socio-demographic characteristics of all participants. Each wave of these surveys used a standard questionnaire with little or no difference between the questionnaires across the waves.

\section{Outcome variables and operational definitions}

The primary outcomes were children with only one severe condition of malnutrition, that is, severe stunting or severe wasting or severely underweight; and children with more than one severe condition of malnutrition (children with two or three conditions). A child was considered to be respectively, severely stunted, severely wasted and severely underweight if the height-for-age, weight-for-height, and weight-for-age indices were 3 SDs or more below the respective median of the WHO reference population (Kandala et al., 2011). Children were categorized 0.0 for normal and 1.0 for severe malnutrition for three indicators each. After that, the values of all three indicators were added, which resulted in a score ranging from 0 to 3 . The scores were again recategorized as 0 for normal, 1 for only one severe form of severe malnutrition and 2 to 3 for multiple forms of severe malnutrition. 


\section{Independent variables}

A selection of socio-demographic variables that could be consistently measured across the three surveys and were found to be important in the literature were used to fit both unadjusted and adjusted models (Chowdhury et al., 2016; Aguayo et al., 2015; Islam et al., 2013; Jesmin et al., 2011; Kandala et al., 2011; Rahman et al., 2012; Pongou et al., 2006; Smith et al., 2005). The variables were age of child (0-11 months, 12-23 months, 24-35 months, 3647 months, 48-59 months); sex of child (male, female); mothers' education (no education, primary, secondary, higher); fathers' employment status (currently not working such as, unemployed, students etc; labourers, such as farmers, agricultural workers, fishermen and rickshaw operators; service holders such as doctors, lawyers, accountants, teachers and businessmen); mothers' working status (currently not working, currently working); watching television (not at all and do not know, less than once a week, at least once a week, all most every day); source of water (tube well, pipe connection and natural sources such as river/dam/lake/ponds/stream/canal/irrigation/well/spring, plus others such as rain water, tanker water, bottle water etc.); solid waste used in cooking (no, yes); intimate partner violence) (no, yes) and birth cohorts (in 2005 and before, 2006-2008, 2009-2011, 2012-2014). Household socioeconomic status was based on the wealth index (poorest, poorer, middle, richest, richer) and community characteristics included such as the place of residence (urban, rural). In BDHSs, IPV was estimated and measured using a shortened and modified version of the Conflict Tactics Scale (Rahman et al., 2012) and based on available information such as physical violence and sexual violence. Physical violence included a wife being beaten if she went out without telling her partner, if she neglected the children and if she ever argued with her partner. The incidence of sexual violence was calculated on a women's positive response to a question asking whether she had ever been physically forced to have sexual intercourse even when she did not want to. For each of the questions, responses were recoded 
dichotomously: $1=$ yes and $0=$ no. IPV scores were calculated by adding up all four binary IPV indicators, with maximum and minimum values of 4 and 0 , respectively. These estimated scores were then recoded as a binary variable with categories labelled no and yes. Individuals who scored 0.0 were categorized as "not experienced IPV " and those who scored above 1.0 were categorized as "experienced IPV" (Rahman et al., 2012). The wealth index was constructed using information about household assets that were collected in BDHSs. The data on household assets included ownership of durable goods (such as televisions and bicycles) and dwelling characteristics (such as the source of drinking water, sanitation facilities, and construction materials). Principal components analyses were performed to assign individual household wealth scores. These weighted values were then summed and rescaled to range from 0-1, and each household was assigned into quintiles: the first quintile: poorest; the second quintile: poorer; the third quintile: middle class; the fourth quintile: richer and the fifth quintile: richest (Chowdhury et al., 2016).

\section{Statistical analysis}

Descriptive statistics were calculated for identifying socio-demographic characteristics, and a Chi-square test was used for assessing socio-demographic differences in child malnutrition. In all analyses, the significance level was set at $\mathrm{P}<0.05$ (2-tailed). Both unadjusted and adjusted models were developed to analyze the appropriate binary value for each nutritional outcome of children with only one case and multiple cases of malnutrition. In bivariate analysis, all independent variables were taken into account. However, all independent variables except, sex, source of water and solid waste used in cooking were simultaneously entered into the multiple regression models for adjustment as sex was not significant in bivariate analysis and source of water and solid waste used in cooking were proxy variables of wealth index. In addition, all the variables that were considered for the analysis were 
independent variables, and no control group was taken into consideration in this study. Odds ratios (ORs) were produced to assess the strength of associations and 95\% confidence intervals (CIs) were used for significance testing. An examination of the standard errors of the regression coefficients was performed to check for multicollinearity in the logistic regression analyses. A standard error larger than 2.0 indicated numerical problems such as multicollinearity among the independent variables (Chan, 2004). The standard errors of all of the independent variables in both adjusted models for each outcome were below 1, indicating an absence of multicollinearity. Stata version 14.2 (StataCorp LP, College Station, Texas) was used in conducting all analyses considering the sample weighting based on the complex design of the BDHSs.

\section{Results}

The detailed background characteristics of the respondents are shown in Table 1. About half of the children were male (50.98\%) with seven out of 10 of them from rural areas; around 41.58 $\%$ of mothers with children had completed secondary education; around $40 \%$ of the children were from low-income families with a similar number from affluent families. The percentages for non-educated mothers, working mothers and mothers that had experienced IPV were around $20.0 \%, 19.0 \%$ and $31.52 \%$ respectively. The principal category for father's employment was labour $(70.0 \%)$ and about two-fifths $(42.57 \%)$ of mothers did not watch television. Tube well water was used for drinking in around eight out of ten households with a similar number observed using solid waste for household cooking. Figure 2 showed the prevalence of malnutrition in moderate and severe form as well as the prevalence of single case and multiple cases based on the 2014 BDHS survey. Figure 2 also discovered that five out of ten children had various forms of malnutrition whereas only two per cent of children had only one form of malnutrition. 
The proportion of children with only one severe form of malnutrition was around $11.53 \%$, whereas the proportion of those with multiple forms was approximately $7.62 \%$ (Table 1). According to the results of the Chi-square test, all selected variables apart from the sex of child were significantly associated with both one severe adverse nutritional outcome and multiple severe adverse nutritional outcomes. The proportions for both forms of adverse nutritional outcomes were significantly higher in the older age groups. The proportions of only one severe form of malnutrition were significantly higher among children with mothers that were uneducated $(15.43 \%)$ and currently not working mothers $(11.73 \%)$, mothers experiencing IPV $(12.66 \%)$ and children whose mothers did not watch television at all (14.57\%). The proportion was also higher among children whose fathers were employed in labour type jobs $(12.63 \%)$.

Similarly, households with children that collected drinking water from natural sources $(14.61 \%)$ and used solid waste for cooking $(12.00 \%)$ were found to have significantly higher proportions. The proportions were higher among children from the poorest families $(16.84 \%)$ and rural dwellers (12.25\%). Lastly, the proportion of only one severe adverse nutritional outcome was higher among children of birth cohorts 2005 and before (12.25\%). Similar results were obtained for children with multiple forms of severe malnutrition. In this case, significantly higher proportions were observed among children in the categories of uneducated mothers (12.48\%) and currently not working mothers (8.09\%), mothers did not watch television at all $(10.06 \%)$ and mothers experiencing IPV $(8.81 \%)$. The proportion of children with multiple severe forms of malnutrition was also higher for those whose fathers were employed in labour type jobs $(8.75 \%)$. Similarly, the proportions were found to be significantly higher in categories of other variables, such as natural sources of drinking water $(12.35 \%)$, used solid waste for 
cooking (12.35\%), children of households from poorest families $(12.64 \%)$ and rural dwellers $(8.44 \%)$. Also, the proportion of children with multiple severe adverse nutritional outcomes was higher among children in the 2005 birth cohorts and before (10.63\%).

\section{Results of logistic regression analysis}

Logistic regression analysis was performed to identify the effects of selected sociodemographic variables on both cases of severe child malnutrition. According to the results of unadjusted models from the logistic regression analysis in Table 2, age of child, mothers' education, fathers' occupation, watching television, IPV, wealth index, place of residence and birth cohorts had significant effects on children with only one form of severe malnutrition. In the adjusted model, age of a child, mothers' education, mothers' working status, watching television, wealth index, place of residence and birth cohorts had significant effects on children with only one severe form (Table 2). In Table 3, unadjusted logistic regression models showed that age of child, mothers' education, fathers' occupation, watching television, IPV, wealth index, place of residence and birth cohorts had significant effects on children with multiple forms. In adjusted model, age of child, mothers' education, fathers' occupation, watching television, wealth index, and birth cohorts had significant effects on children with multiple case (Table 3). However, significant variations in effects among the categories of some variables were observed between the two cases.

In Table 2 and Table 3, children in the youngest age group appeared to be less at risk of developing severe adverse nutritional outcomes in both cases; children of uneducated mothers were 2.59 (OR: $2.59,95 \% \mathrm{CI}=1.98$-3.38) times more likely to have only one severe form of malnutrition (Table 2) whereas those with a higher educated mother were 3.22 (OR: 3.22, 95\% CI=2.22-4.67) times more likely to have multiple forms of severe malnutrition (Table 3). Children whose fathers were service holders were around 50\% (OR: 0.52, 95\% 
$\mathrm{CI}=0.32-0.84$ ) less likely to have multiple forms of severe malnutrition than were those with fathers who were businessmen (Table 3), whereas, fathers' occupation did not show any significant effect for only one form of severe case (Table 2). Children of mothers who are currently working were 0.83 (OR: $0.83,95 \% \mathrm{CI}=0.73-0.95)$ times less likely to have only one form of severe child malnutrition (Table 2), on the other hand, mother's working status was found insignificant in terms of multiple cases (Table 3). Mothers who did not watch television at all were $1.28(\mathrm{OR}: 1.28,95 \% \mathrm{CI}=1.02-1.62)$ times more likely to have only one severe case compared to the mothers who watched television every day (Table 2). Mothers who did not watch television at all were $1.36(\mathrm{OR}: 1.36,95 \% \mathrm{CI}=1.03-1.82)$ times more likely to have multiple forms of severe malnutrition (Table 3). Children from poor families suffered multiple forms of severe malnutrition and were more vulnerable than those from rich families. Children from poor families who were recorded as having one form of severe malnutrition were less vulnerable (Table 2) compared to children from poor families with multiple forms of severe malnutrition (Table 3). In both cases, the likelihood of there being severe adverse nutritional outcomes among children followed declining trends from previous birth cohorts to recent birth cohorts.

\section{Discussion}

This study demonstrates the epidemiological difference of severe malnutrition among children aged under-five in Bangladesh with only one form or multiple forms of severe malnutrition together with socio-demographic risk factors. The proportion of children with only one form of severe malnutrition was approximately $12 \%$ whereas the proportion for multiple forms of severe malnutrition was around $8 \%$. Of all the study variables, with the exception of the gender of a child, the proportions were estimated to be higher for one form of severe malnutrition compared to those with multiple forms of severe malnutrition. However, one form of severe 
malnutrition and multiple forms were both significantly associated with age of child, mothers' education, fathers' occupation, mothers currently working, watching television, source of water, solid waste used in cooking, IPV, wealth index, place of residence and birth cohort. Various studies conducted in Bangladesh and other regions revealed that most of the selected variables used in this study are significantly associated with different malnutrition indicators, such as stunting, wasting and being underweight along with severe malnutrition indicators, for example, severe stunting, severe wasting and being severely underweight (Islam et al., 2019; Sultana et al., 2019; Akombi et al., 2017; Das \& Gulshan, 2017; Pravana et al., 2017; Chowdhury et al., 2016; Aguayo et al., 2015; Rahman et al., 2012; Kandala et al., 2011). More specifically, in other studies, age and sex of children, mothers' education and occupation, toilet facilities, source of drinking water, place of residence and socioeconomic status were found to be significantly associated with stunting, wasting and being underweight in children aged under-five (Das \& Gulshan, 2017; Chowdhury et al., 2016). In another study, mothers' education, fathers'education, place of residence and socioeconomic status were found to be significantly associated with severe malnutrition in Bangladesh (Talukder, 2017). A child's age, maternal education, maternal occupation and paternal occupation were found to be significantly associated with any form of malnutrition in Bangladesh (Hossain \& Khan, 2018). In a study by Islam et al (2019) conducted in Bangladesh, a child's age, sex of child, mothers' education, fathers' education, place of residence and socioeconomic status were found to be significantly associated with severe stunting, severe wasting and being severely underweight. In a study conducted in Nepal, Pravana et al. (2017) found that the mothers' educational status, fathers' educational status and socioeconomic status were significantly associated with severe wasting. Although these particular studies explored the associations between various sociodemographic variables and single or precise malnutrition indicators (e.g. stunting, wasting, underweight, severe stunting, severe wasting and severely underweight), the findings were not 
analogous with the present study. The inspiration for conducting this study was provided by research was undertaken by Myatt et al. (2018) and McDonald et al. (2013) respectively that were based on large data obtained from 51 countries plus anonymized data from 10 prospective studies in the following countries: Bangladesh, Ghana, Guinea-Bissau, India, Indonesia, Nepal, Peru, the Philippines, Senegal, and Sudan. However, these two studies were generated on the basis of the association between simultaneous multiple anthropometric deficits and the risk of mortality. It would appear that there are no studies that have highlighted the significant association between socio-demographic factors and severe child malnutrition involving both one form and multiple forms.

The study revealed that the proportion of multiple severe forms of malnutrition were significantly lower among the youngest children as compared to others. The prevalence of malnutrition found to be lower in the younger age group has been demonstrated by other studies conducted in Bangladesh and Africa (Chowdhury et al., 2016; Islam et al., 2013; Mengistu et al., 2013; Olack et al., 2011). In the second year of life, children receive a family diet along with breast milk and are often allowed to eat food for themselves but do not always have access to adequate amounts of solid food that may contribute to their poor nutritional status (Hong et al., 2006). Alternatively, the proportion of multiple severe forms of malnutrition were significantly higher among children where mothers were not educated, where fathers had labour occupations and where mothers were currently working. These findings were identical in terms of severe malnutrition with multiple forms. However, the prevalence of malnutrition among children with specific forms (such as stunting, wasting and being underweight) was shown to be higher among children in Bangladesh, Mexico and Pakistan where mothers were not educated, fathers were in labour occupations, and mothers were currently working (Islam et al., 2019; Khattak et al., 2017; Reyes et al., 2004). Such a relationship could exist because maternal schooling and employment status are strongly associated with good childcare and 
good health. Women's autonomy is deeply embedded with their educational attainment and employment status that indirectly impacts on the growth parameters of their children (Senarath \& Gunawardena, 2009). Women with higher educational attainment can make a very positive contribution through raising the family income that then helps to provide a better quality diet and better healthcare for their children compared to women at a lower educational level (Islam et al., 2013). Educational attainment, therefore, along with employment status, can have a positive and significant effect on child malnutrition. However, low paid women with poor educational status are not in a position to provide a proper nutritional diet for their children. However, these findings were not universally observed. In Bangladesh, men are generally stereotypically considered to be the main family earner. Despite women's employment status following an increasing trend due to the flourishing garment sector, family income is still strongly associated with the fathers' occupation. It could be expected that fathers with lowlevel jobs when compared to those fathers with more prestigious jobs, would have poorer levels of income. Therefore their children would consequently have a poor nutritional status (Islam et al., 2013). The study also shows that the proportions of multiple severe forms of malnutrition were significantly higher among mothers of children that were experiencing IPV. Maternal IPV was found to be associated with an increased risk of stunting, wasting and being underweight among children in Bangladesh, India and Brazil (Rahman et al., 2012; Ackerson \& Subramanian, 2008; Hasselmann \& Reichenheim, 2006). In a study in Bangladesh by Rahman et al (2012), all forms of IPV were found to be strongly responsible for long-term adverse mental health issues among mothers including stress, depression, and anxiety that led to an inability to cope with the everyday needs of a small child, diminished the quality of their caregiving behaviours so leading to negative health consequences for their children. Again, the proportions were significantly higher for members of households, including children that did not watch television, where drinking water was obtained from natural sources, and solid waste 
was used for cooking. Documentation of the association between child malnutrition and mass media exposure, as well as between child malnutrition and source of water, are limited. However, in Bangladesh, Chowdhury et al. (2016) established a significant relationship between poor mass media exposure and inadequate complementary feeding that has an indirect effect on child malnutrition while Islam et al. (2013) found a significant association between child malnutrition and source of water. Safe drinking water is a pre-condition of proper nutritional status as various waterborne diseases can be transmitted through contaminated water, including ponds and rivers (WASH, 2007). Two studies found child malnutrition was associated with some types of solid waste used in cooking (Kyu et al., 2009; Mishra \& Retherford, 2006). Nearly four million people die prematurely each year from illnesses attributable to household air pollution due to inefficient cooking practices (WHO, 2018). The use of solid fuels for cooking can adversely affect deep into the lungs, and for women, its use can indirectly lead to low weights in newborns (WHO, 2018). The study also explored the higher proportions of children from poorer sections of society, in rural settlements and from birth cohorts of 2005 and before that were suffering multiple forms of severe malnutrition. Some studies were reviewed to harmonize the findings from this study, and it was identified that the prevalence of child malnutrition was significantly higher among socioeconomically low-income families and rural settlers (Islam et al., 2019; Khan et al., 2019; Chowdhury et al., 2016). Socioeconomic status is, therefore, a key element for influencing the rate of malnutrition in children. The reasons for this include the limited capacity of poorer families to access essential healthcare services, lack of potable water and adequate sanitation, poor housing facilities and nutritionally inadequate diets (Islam et al., 2019). A study of rural areas in Mexico highlighted that the variable father's occupation (labour/farmer) was found to be a risk factor in child malnutrition (Reyes et al., 2004). Also, the availability of food in rural areas depends 
upon local production that, in turn, is related to the father's occupation. Lack of food variability or inability to produce enough food may, therefore, lead to adverse nutritional outcomes.

The multivariable logistic regression analysis identified several determinants of severe child malnutrition with only one form and with multiple forms, such as age of the child, mothers' education, watching television, wealth index and provoking severe adverse nutritional outcomes for both forms. These factors were also identified as significant predictors by other studies, particularly for single malnutrition and severe malnutrition indicators (Islam et al., 2019; Das \& Gulshan, 2017; Nkurunziza et al., 2017; Pravana et al., 2017; Talukder, 2017; Tiwari et al., 2014; Rahman et al., 2012). Mothers' working status and place of residence had significant effects on children with only one severe form which were found insignificant in terms of children with multiple case. Fathers' occupation appeared to have a significant effect on children with multiple forms of severe malnutrition which was not significant for only one form. This distinctive result was observed after clustering the various forms of severe child malnutrition into two outcome measures. However, in Bangladesh, Islam et al. (2013) found that fathers' occupation had insignificant effects on child malnutrition in Bangladesh. In this study, birth cohorts had significant effects on child malnutrition for both only one severe form and multiple forms that have not been previously documented and children born before 2005 had a higher risk of multiple forms of severe malnutrition. The implementation of advanced strategies and active policy initiatives aimed at eradicating hunger and malnutrition in order to meet SDG goals might be a reason for improvements in the current decade.

The epidemiological insights provided in this study demonstrate the extent, severity and distribution of severe malnutrition with only one form and multiple forms. These insights can help with the allocation of human and financial resources for effective implementation of policies and programmes aimed at reducing severe child malnutrition. Concerted efforts to 
forge a strong collaboration between government, non-government, social, cultural, and religious institutions are essential in order to strengthen nutritional campaigns, especially in rural areas. Bangladesh's "'"National Social Security Strategy"'" needs to be revised to include nutritional protection in order to provide appropriate support to its most vulnerable citizens (Chowdhury et al., 2016). The existing Bangladesh National Nutrition Policy (2015) needs to be modernized to help address malnutrition (FAO, 2015). More research is urgently needed to explore how the environment interacts with child malnutrition, especially in the case of water, sanitation and use of solid waste for cooking (Vilcins et al., 2018).

The present study has several strengths and limitations. The main strength is that the data came from large, nationally representative household surveys carried out in 2007, 2011 and 2014 that covered both urban and rural areas. As a result, this study was able to generalize the findings for Bangladesh with limited bias. Besides, this study provides new data regarding severe child malnutrition that has not been significantly addressed before. However, along with the strengths as mentioned above, this study has certain limitations. It was not possible to establish a causal relationship between risk factors and the dependent variables due to the crosssectional nature of the study. In addition, the current nutritional situation could not be explored due to the unavailability of more recent data. The implausibility of stunting, wasting, and being underweight was defined based on the most inclusive standards flag limits of WHO that may result in the highest reported prevalence. Another limitation involves information bias that may result from collecting data on self-reported age, education, occupation, and household assets etc.

In conclusion, the prevalence of severe malnutrition in under-five years old children living in Bangladesh is one of the highest in the world. Several risk factors such as age, mothers' education, watching television, wealth index, and birth order have been identified. 
These findings need to be prioritized when designing evidence-based programmes for successfully eradicating severe malnutrition in children aged under-five years. However, this study has taken in account the indicators which were previously identified. After classifying the various forms of severe child malnutrition into two outcome measures, the determinants were not identical for both cases. Therefore, these facts need to be considered while formulation and implication of the policies to address the issue.

Finally, in Bangladesh, as well as in the rest of the developing world, further investigation is needed into severe malnutrition (eg prospective cohort studies). Such research should help to inspire ingenuity when developing effective strategies to improve the nutritional status of children under-five years of age.

\section{Acknowledgement}

The authors would like to thank the Demographic Health Survey for permission to use the data and the Graduate School of the University of West London, the United Kingdom for giving the scope of the research under the Commonwealth Split-site Scholarship of Commonwealth Scholarship Commissions.

\section{Conflicts of interest}

The authors have no conflicts of interest to declare.

\section{Funding}

This research received no specific grant from any funding agency, commercial entity or notfor-profit organization. 


\section{Ethical approval}

The BDHSs was reviewed and approved by the ICF Macro Institutional Review Board (USA), which complies with all of the requirements of 45 CFR 46 "'"Protection of Human Subjects"" ". The Bangladesh DHS was also reviewed and approved by the National Research Ethics Committee of the Bangladesh Medical Research Council (Dhaka, Bangladesh). Informed consent was also obtained verbally from each participant (every married woman aged 15-49 years old) before being enrolled on the study. A significant number of the study sample was illiterate, and so verbal consent was considered the most suitable option to confirm participation. The BDHSs also included samples of very young children (under five-year-old children either born in 2002 or later) in the data collection and so mothers of these samples were asked to provide verbal consent on behalf of their children. 


\section{References}

Ackerson LK and Subramanian SV (2008) Domestic violence and chronic malnutrition among women and children in India. American Journal of Epidemiology 167(10), 1188-1196. doi:10.1093/aje/kwn049

Aguayo VM, Badgaiyan N and Paintal K (2015). Determinants of child stunting in the Royal Kingdom of Bhutan: an in-depth analysis of nationally representative data. Maternal and Child Nutrition 11(3), 333-345. doi:10.1111/mcn.12168

Akombi BJ, Agho KE, Hall JJ, Merom D, Astell-Burt T and Renzaho AM (2017). Stunting and severe stunting among children under-5 years in Nigeria: A multilevel analysis. BMC pediatrics 17(1), 15.

Bhutta ZA (2017) Global child nutrition and the Sustainable Development Goals. Lancet Child and Adolescent Health 1(4), 256-257. doi:10.1016/s2352-4642(17)30119-0

Black RE, Victora CG, Walker SP, Bhutta ZA, Christian P, de Onis M, .. U Uauy R (2013) Maternal and child undernutrition and overweight in low-income and middleincome countries. Lancet 382(9890), 427-451. doi:10.1016/s0140-6736(13)60937-x

Chan Y (2004) Biostatistics 202: logistic regression analysis. Singapore medical journal 45(4), 149-153.

Chowdhury MR, Rahman MS and Khan MM (2016) Levels and determinants of complementary feeding based on meal frequency among children of 6 to 23 months in Bangladesh. BMC Public Health 16, 944. doi:10.1186/s12889-016-3607-7

\section{Chowdhury MR, Rahman MS, Khan MM, Mondal MN, Rahman MM and Billah B} (2016) Risk Factors for Child Malnutrition in Bangladesh: A Multilevel Analysis of a Nationwide Population-Based Survey. Journal of Pediatrics 172, 194-201.e191. doi:10.1016/j.jpeds.2016.01.023 
Das S and Gulshan J (2017) Different forms of malnutrition among under five children in Bangladesh: a cross sectional study on prevalence and determinants. BMC Nutrition 3(1), 1 .

Development Initiatives (2018) 2018 Global Nutrition Report: Shining a light to spur action on nutrition. Retrieved from https://globalnutritionreport.org/reports/global-nutritionreport-2018/ (Access date: December 11, 2019)

FAO (2015) National Nutrition Policy 2015. Nutrition Is the Foundation for Development. Food and Agriculture Organization. Retrieved from http://extwprlegs1.fao.org/docs/pdf/bgd152517.pdf (Access date: December 24, 2019)

Hasselmann MH and Reichenheim ME (2006) Parental violence and the occurrence of severe and acute malnutrition in childhood. Paediatric and Perinatal Epidemiology 20(4), 299-311. doi:10.1111/j.1365-3016.2006.00735.x

Hong R, Banta JE, and Betancourt JA (2006) Relationship between household wealth inequality and chronic childhood under-nutrition in Bangladesh. International Journal of Equity Health 5, 15. doi:10.1186/1475-9276-5-15

Hossain MB and Khan MHR (2018) Role of parental education in reduction of prevalence of childhood undernutrition in Bangladesh. Public Health Nutrition 21(10), 18451854. doi:10.1017/s1368980018000162

Islam A and Biswas T (2015) Chronic stunting among under-5 children in Bangladesh: A situation analysis. Advances in Pediatric Research 2, 18.

\section{Islam MM, Alam M, Tariquzaman M, Kabir MA, Pervin R, Begum M and Khan MM} (2013) Predictors of the number of under-five malnourished children in Bangladesh: application of the generalized poisson regression model. BMC Public Health 13, 11. doi:10.1186/1471-2458-13-11 
Islam MR, Rahman MS, Rahman MM, Nomura S, de Silva A, Lanerolle P, . . Rahman MM (2019) Reducing childhood malnutrition in Bangladesh: the importance of addressing socioeconomic inequalities. Public Health Nutrition 1-11. doi:10.1017/s136898001900140x

Jesmin A, Yamamoto SS, Malik AA and Haque MA (2011) Prevalence and determinants of chronic malnutrition among preschool children: a cross-sectional study in Dhaka City, Bangladesh. J Health Popullation and Nutrition 29(5), 494-499. doi:10.3329/jhpn.v29i5.8903

Kandala NB, Madungu TP, Emina JB, Nzita, KP and Cappuccio FP (2011) Malnutrition among children under the age of five in the Democratic Republic of Congo (DRC): does geographic location matter? BMC Public Health 11, 261. doi:10.1186/14712458-11-261

Khan S, Zaheer S and Safdar NF (2019) Determinants of stunting, underweight and wasting among children $<5$ years of age: evidence from 2012-2013 Pakistan demographic and health survey. BMC Public Health 19(1), 358.

Khattak UK, Iqbal SP and Ghazanfar H (2017) The Role of Parents' Literacy in Malnutrition of Children Under the Age of Five Years in a Semi-Urban Community of Pakistan: A Case-Control Study. Cureus 9(6).

Kyu HH, Georgiades K and Boyle MH (2009) Maternal smoking, biofuel smoke exposure and child height-for-age in seven developing countries. International Journal of Epidemiology 38(5), 1342-1350.

Madhusudhan K, Shireesha ARPK and Ushashree GV (2017) Study of risk factors of severe acute malnutrition (SAM) in children 6 months to 5 years of age and evaluation of effect of micronutrient supplementation (WHO protocol) on serum zinc 
and magnesium levels: a case control study. International Journal of Contemporary Pediatrics 4(4), 8. doi:http://dx.doi.org/10.18203/2349-3291.ijcp20172112

\section{McDonald CM, Olofin I, Flaxman S, Fawzi WW, Spiegelman D, Caulfield LE, ...}

Danaei, G (2013) The effect of multiple anthropometric deficits on child mortality: meta-analysis of individual data in 10 prospective studies from developing countries. American Journal of Clinical Nutrition 97(4), 896-901. doi:10.3945/ajen.112.047639

Mengistu K, Alemu K and Destaw B (2013) Prevalence of malnutrition and associated factors among children aged 6-59 months at Hidabu Abote District, North Shewa, Oromia Regional State. Journal of nutritional disorders and therapy 1, 1-15.

Mishra V and Retherford RD (2006) Does biofuel smoke contribute to anaemia and stunting in early childhood? International Journal of Epidemiology 36(1), 117-129.

Myatt M, Khara T, Schoenbuchner S, Pietzsch S, Dolan C, Lelijveld N and Briend A (2018) Children who are both wasted and stunted are also underweight and have a high risk of death: a descriptive epidemiology of multiple anthropometric deficits using data from 51 countries. Archives of Public Health 76, 28. doi:10.1186/s13690018-0277-1

Ngari MM, Iversen PO, Thitiri J, Mwalekwa L, Timbwa M, Fegan GW and Berkley JA (2019) Linear growth following complicated severe malnutrition: 1-year follow-up cohort of Kenyan children. Archives of Diseases in Childhood 104(3), 229-235. doi:10.1136/archdischild-2018-315641

NIPORT (2009) Bangladesh Demographic and Health Survey 2007. National Institute of Population Research and Training, Mitra and Associates and Macro International, Dhaka, Bangladesh. Retrieved from https://dhsprogram.com/pubs/pdf/FR207/FR207[April-10-2009].pdf (Access date: December 15, 2019) 
NIPORT (2013) Bangladesh Demographic and Health Survey 2011. National Institute of Population Research and Training, Mitra and Associates and Macro International, Dhaka, Bangladesh. Retrieved from https://dhsprogram.com/pubs/pdf/fr265/fr265.pdf (Access date: December 15, 2019)

NIPORT (2016) Bangladesh Demographic and Health Survey 2014. National Institute of Population Research and Training, Mitra and Associates and Macro International, Dhaka, Bangladesh. . Retrieved from https://dhsprogram.com/pubs/pdf/FR311/FR311.pdf (Access date: December 15, 2019)

Nkurunziza S, Meessen B, Van Geertruyden JP and Korachais C (2017) Determinants of stunting and severe stunting among Burundian children aged 6-23 months: evidence from a national cross-sectional household survey, 2014. BMC Pediatrics 17(1), 176. doi:10.1186/s12887-017-0929-2

Olack B, Burke H, Cosmas L, Bamrah S, Dooling K, Feikin DR, . . Breiman RF (2011) Nutritional status of under-five children living in an informal urban settlement in Nairobi, Kenya. J Health Population and Nutrition 29(4), 357-363. doi:10.3329/jhpn.v29i4.8451

Pongou R, Ezzati M and Salomon JA (2006) Household and community socioeconomic and environmental determinants of child nutritional status in Cameroon. BMC Public Health 6, 98. doi:10.1186/1471-2458-6-98

Pravana NK, Piryani S, Chaurasiya SP, Kawan R, Thapa RK and Shrestha S (2017) Determinants of severe acute malnutrition among children under 5 years of age in Nepal: a community-based case-control study. BMJ Open 7(8), e017084. doi:10.1136/bmjopen-2017-017084 
Rahman M, Poudel KC, Yasuoka J, Otsuka K, Yoshikawa K and Jimba M (2012)

Maternal exposure to intimate partner violence and the risk of undernutrition among children younger than 5 years in Bangladesh. American Journal of Public Health 102(7), 1336-1345. doi:10.2105/ajph.2011.300396

\section{Reyes H, Perez-Cuevas R, Sandoval A, Castillo R, Santos JI, Doubova SV and Gutierrez G (2004) The family as a determinant of stunting in children living in conditions of extreme poverty: a case-control study. BMC Public Health 4, 57. doi:10.1186/1471- $2458-4-57$}

Senarath U and Gunawardena NS (2009) Women's autonomy in decision making for health care in South Asia. Asia Pacific Journal of Public Health 21(2), 137-143. doi:10.1177/1010539509331590

Smith LC, Ruel MT and Ndiaye A (2005) Why is child malnutrition lower in urban than in rural areas? Evidence from 36 developing countries. World Development 33(8), 12851305.

Sultana P, Rahman MM and Akter J (2019) Correlates of stunting among under-five children in Bangladesh: a multilevel approach. BMC Nutrition 5(1), 41.

Talukder A (2017) Factors associated with malnutrition among under-five children: illustration using Bangladesh demographic and health survey, 2014 data. Children $\mathbf{4}(10), 88$.

Tebeje N, Bikes G, Abebe S and Yesuf M (2017) Prevalence and major contributors of child malnutrition in developing countries: systematic review and meta-analysis. Journal of Childhod Obesity 2(1).

Tiwari R, Ausman LM and Agho KE (2014) Determinants of stunting and severe stunting among under-fives: evidence from the 2011 Nepal Demographic and Health Survey. BMC Pediatrics 14, 239. doi:10.1186/1471-2431-14-239 
UNICEF (2015) Undernutrition contributes to nearly half of all deaths in children under 5 and is widespread in Asia and Africa. Retrived from https://data.unicef.org/topic/nutrition/malnutrition/ (Access date: December 5, 2019) Vilcins D, Sly PD and Jagals P (2018) Environmental Risk Factors Associated with Child Stunting: A Systematic Review of the Literature. Annals Global Health 84(4), 551562. doi:10.29024/aogh.236110.9204/aogh.2361

Walson JL and Berkley JA (2018) The impact of malnutrition on childhood infections. Current opinion in infectious diseases 31(3), 231.

WASH (2007) Interactions of: Malnutrition, Water Sanitation and Hygiene, Infections. Diarrhoea and malnutrition. 1-47. Retrieved from https://www.actionagainsthunger.org/sites/default/files/publications/Malnutrition __WASH__infections_English.pdf (Access date: December 20, 2019)

WHO (2018) Household air pollution and health. World Health Organization. Retrieved from https://www.who.int/news-room/fact-sheets/detail/household-air-pollution-andhealth (Access date: December 29, 2019) 
Table 1. Relationship between socio-demographic factors and under-five severe child malnutrition (only one form and multiple forms)

\begin{tabular}{|c|c|c|c|c|c|}
\hline Variables & $\begin{array}{l}\text { Frequency } \\
(\%)\end{array}$ & $\begin{array}{l}\text { Only one form } \\
\text { of severe } \\
\text { malnutrition }\end{array}$ & $\begin{array}{l}\text { Multiple forms } \\
\text { of severe } \\
\text { malnutrition }\end{array}$ & $\begin{array}{c}\mathbf{P} \\
\text { values }\end{array}$ & $\begin{array}{l}\text { Phi coefficient } \\
\text { and Cramer's V }\end{array}$ \\
\hline \multicolumn{6}{|l|}{ Children age } \\
\hline $0-11$ months & $3,872(19.48)$ & $318(8.21)$ & $149(3.85)$ & 0.001 & 0.091 \\
\hline $12-23$ months & $3,986(20.06)$ & $500(12.54)$ & $324(8.13)$ & & \\
\hline 24-35 months & $3,911(19.68)$ & $506(12.94)$ & $360(9.20)$ & & \\
\hline 36-47 months & $4,094(20.60)$ & $526(12.85)$ & $384(9.38)$ & & \\
\hline 48-59 months & $4,011(20.18)$ & 441 (10.99) & $294(7.33)$ & & \\
\hline \multicolumn{6}{|l|}{ Sex of child } \\
\hline Male & $10,132(50.98)$ & $1,172(11.57)$ & $754(7.44)$ & 0.856 & 0.003 \\
\hline Female & $9,742(49.02)$ & $1,119(11.49)$ & $757(7.77)$ & & \\
\hline \multicolumn{6}{|l|}{ Mothers' education } \\
\hline No education & $3,941(19.83)$ & $608(15.43)$ & $492(12.48)$ & 0.001 & 0.130 \\
\hline Primary & $5,912(29.75)$ & $831(14.06)$ & $569(9.62)$ & & \\
\hline Secondary & $8,264(41.58)$ & $758(9.17)$ & $410(4.96)$ & & \\
\hline Higher & $1,757(8.84)$ & $94(5.35)$ & $40(2.28)$ & & \\
\hline \multicolumn{6}{|l|}{ Fathers' occupation } \\
\hline Currently not working & $502(2.53)$ & $45(8.96)$ & $32(6.37)$ & 0.001 & 0.078 \\
\hline Labour & $13,756(69.22)$ & $1,738(12.63)$ & $1,203(8.75)$ & & \\
\hline Service & $1,132(5.70)$ & $73(6.45)$ & $21(1.86)$ & & \\
\hline Business & $4,484(22.56)$ & $435(9.70)$ & $255(5.69)$ & & \\
\hline \multicolumn{6}{|l|}{ Mothers' working status } \\
\hline Currently not working & $16,141(81.22)$ & $1,894(11.73)$ & $1,209(7.49)$ & 0.001 & 0.020 \\
\hline Currently working & $3,733(18.78)$ & $397(10.63)$ & $302(8.09)$ & & \\
\hline \multicolumn{6}{|l|}{ Watching television } \\
\hline Not at all and do not know & $8,460(42.57)$ & $1,233(14.57)$ & $851(10.06)$ & 0.001 & 0.097 \\
\hline Less than once a week & $1,885(9.48)$ & $208(11.03)$ & $175(9.28)$ & & \\
\hline At least once a week & $7,924(39.87)$ & $711(8.97)$ & $403(5.09)$ & & \\
\hline all most everyday & $1,605(8.08)$ & $139(8.66)$ & $82(5.11)$ & & \\
\hline \multicolumn{6}{|l|}{ Source of water } \\
\hline Tube well & $15,947(80.24)$ & $1,866(11.70)$ & $1,237(7.76)$ & 0.001 & 0.041 \\
\hline Pipe connection & $1,549(7.79)$ & $149(9.62)$ & $89(5.75)$ & & \\
\hline Natural sources & $486(2.45)$ & $71(14.61)$ & $60(12.35)$ & & \\
\hline Others & $1,892(9.52)$ & $205(10.84)$ & $125(6.61)$ & & \\
\hline \multicolumn{6}{|c|}{ Solid waste use in cooking } \\
\hline No & $4,022(20.24)$ & $389(9.67)$ & $213(5.30)$ & 0.001 & 0.056 \\
\hline Yes & $15,852(79.76)$ & $1,902(12.00)$ & $1,298(8.19)$ & & \\
\hline \multicolumn{6}{|l|}{ IPV } \\
\hline No & $13,609(68.48)$ & $1,498(11.01)$ & $959(7.05)$ & 0.001 & 0.031 \\
\hline Yes & $6,265(31.52)$ & $793(12.66)$ & $552(8.81)$ & & \\
\hline \multicolumn{6}{|l|}{ Wealth index } \\
\hline Poorer & $4,241(21.34)$ & $714(16.84)$ & $536(12.64)$ & 0.001 & 0.136 \\
\hline Poor & $3,877(19.51)$ & $504(13.00)$ & $356(9.18)$ & & \\
\hline Middle & $3,825(19.25)$ & $424(11.08)$ & $295(7.71)$ & & \\
\hline Richer & $3,900(19.62)$ & $370(9.49)$ & $198(5.08)$ & & \\
\hline Richest & $4,031(20.28)$ & $279(6.92)$ & $126(3.13)$ & & \\
\hline \multicolumn{6}{|l|}{ Place of residence } \\
\hline Urban & $6,362(32.01)$ & $636(10.00)$ & $371(5.83)$ & 0.001 & 0.091 \\
\hline Rural & $13,512(67.99)$ & $1,655(12.25)$ & $1,140(8.44)$ & & \\
\hline \multicolumn{6}{|l|}{ Birth cohorts } \\
\hline$<=2005$ & 3,781 (19.02) & 487 (12.88) & $402(10.63)$ & 0.001 & 0.057 \\
\hline $2006-2008$ & $5,123(25.78)$ & 568 (11.09) & $416(8.12)$ & & \\
\hline 2009-2011 & $7,217(36.31)$ & 857 (11.87) & $490(6.79)$ & & \\
\hline $2012-2014$ & $3,753(18.88)$ & $379(10.10)$ & $203(5.41)$ & & \\
\hline Total & $19,874(100.00)$ & $2,291(11.53)$ & $1,511(7.60)$ & & \\
\hline
\end{tabular}


Table 2. Results of unadjusted and adjusted models for risk factors of severe child malnutrition with only one form

\begin{tabular}{|c|c|c|c|c|}
\hline \multirow[t]{2}{*}{ Variables } & \multicolumn{4}{|c|}{ Only one severe adverse nutritional outcome $(\mathrm{N}=11,927)$} \\
\hline & Unadjusted OR (95\% CI) & P values & Adjusted OR (95\% CI) & $P$ values \\
\hline \multicolumn{5}{|l|}{ Children age } \\
\hline $0-11$ months & $0.54(0.46-0.63)$ & $<0.001$ & $0.59(0.50-0.70)$ & 0.001 \\
\hline $12-23$ months & $1.16(1.00-1.33)$ & 0.047 & $1.33(1.33-1.56)$ & $<0.001$ \\
\hline 24-35 months & $1.27(1.10-1.46)$ & 0.001 & $1.41(1.21-1.65)$ & $<0.001$ \\
\hline 36-47 months & $1.26(1.09-1.45)$ & 0.001 & $1.38(1.17-1.63)$ & $<0.001$ \\
\hline $48-59$ months & 1.00 & & 1.00 & \\
\hline \multicolumn{5}{|l|}{ Mothers' education } \\
\hline No education & $5.54(4.40-6.97)$ & $<0.001$ & $2.59(1.98-3.38)$ & $<0.001$ \\
\hline Primary & $4.53(3.62-5.67)$ & $<0.001$ & $2.45(1.89-3.16)$ & $<0.001$ \\
\hline Secondary & $2.19(1.75-2.74)$ & $<0.001$ & $1.56(1.22-1.99)$ & $<0.001$ \\
\hline Higher & 1.00 & & 1.00 & \\
\hline \multicolumn{5}{|l|}{ Fathers' occupation } \\
\hline Currently not working & $0.93(0.67-1.30)$ & 0.673 & $0.81(0.58-1.14)$ & 0.229 \\
\hline Labour & $1.58(1.40-1.77)$ & $<0.001$ & $1.11(0.98-1.25)$ & 0.109 \\
\hline Service & $0.52(0.40-0.68)$ & $<0.001$ & $0.91(0.69-1.20)$ & 0.502 \\
\hline Business & 1.00 & & 1.00 & \\
\hline \multicolumn{5}{|l|}{ Mothers' working status } \\
\hline Currently not working & 1.00 & & 1.00 & \\
\hline Currently working & $0.97(0.86-1.10)$ & 0.646 & $0.83(0.73-0.95)$ & 0.005 \\
\hline \multicolumn{5}{|l|}{ Watching television } \\
\hline Not at all and do not know & $2.40(1.99-2.90)$ & 0.512 & $1.28(1.02-1.62)$ & 0.035 \\
\hline Less than once a week & $1.63(1.29-2.06)$ & $<0.001$ & $1.06(0.81-1.39)$ & 0.654 \\
\hline At least once a week & $1.07(0.87-1.30)$ & $<0.001$ & $1.02(0.82-1.28)$ & 0.858 \\
\hline all most everyday & 1.00 & & 1.00 & \\
\hline \multicolumn{5}{|l|}{ IPV } \\
\hline No & 1.00 & & 1.00 & \\
\hline Yes & $1.29(1.17-1.42)$ & $<0.001$ & $1.06(0.96-1.18)$ & 0.262 \\
\hline \multicolumn{5}{|l|}{ Wealth index } \\
\hline Poorer & $4.61(3.96-5.37)$ & $<0.001$ & $2.76(2.41-2.39)$ & $<0.001$ \\
\hline Poor & $3.02(2.58-3.54)$ & $<0.001$ & $2.07(1.79-2.54)$ & $<0.001$ \\
\hline Middle & $2.24(1.91-2.64)$ & $<0.001$ & $1.73(1.43-2.09)$ & $<0.001$ \\
\hline Richer & $1.67(1.42-1.97)$ & $<0.001$ & $1.45(1.21-1.73)$ & $<0.001$ \\
\hline Richest & 1.00 & & 1.00 & \\
\hline \multicolumn{5}{|l|}{ Place of residence } \\
\hline Urban & 1.00 & & 1.00 & \\
\hline Rural & $1.48(1.34-1.63)$ & $<0.001$ & $0.88(0.78-0.99)$ & 0.034 \\
\hline \multicolumn{5}{|l|}{ Birth cohorts } \\
\hline$<=2005$ & 1.00 & & 1.00 & \\
\hline $2006-2008$ & $0.72(0.63-0.82)$ & $<0.001$ & $0.85(0.73-1.00)$ & 0.048 \\
\hline 2009-2011 & $0.75(0.66-0.85)$ & $<0.001$ & $0.91(0.78-1.06)$ & 0.224 \\
\hline $2012-2014$ & $0.58(0.50-0.67)$ & $<0.001$ & $0.75(0.63-0.92)$ & 0.003 \\
\hline
\end{tabular}


Table 3. Results of unadjusted and adjusted models for risk factors of severe child malnutrition with multiple form

\begin{tabular}{|c|c|c|c|c|}
\hline \multirow[t]{2}{*}{ Variables } & \multicolumn{4}{|c|}{ Multiple severe adverse nutritional outcomes $(\mathrm{N}=11,147)$} \\
\hline & Unadjusted OR $(95 \% \mathrm{CI})$ & P values & Adjusted OR (95\% CI) & P values \\
\hline \multicolumn{5}{|l|}{ Children age } \\
\hline $0-11$ months & $0.38(0.31-0.47)$ & $<0.001$ & $0.47(0.38-0.59)$ & $<0.001$ \\
\hline $12-23$ months & $1.12(0.95-1.33)$ & 0.178 & $1.48(1.22-1.80)$ & $<0.001$ \\
\hline 24-35 months & $1.35(1.14-1.60)$ & $<0.001$ & $1.65(1.37-1.98)$ & $<0.001$ \\
\hline $36-47$ months & $1.38(1.17-1.63)$ & $<0.001$ & $1.42(1.19-1.69)$ & $<0.001$ \\
\hline 48-59 months & 1.00 & & 1.00 & \\
\hline \multicolumn{5}{|l|}{ Mothers' education } \\
\hline No education & $10.53(7.57-14.67)$ & $<0.001$ & $3.22(2.22-4.67)$ & $<0.001$ \\
\hline Primary & $7.30(5.26-10.13)$ & $<0.001$ & $2.72(1.89-3.91)$ & $<0.001$ \\
\hline Secondary & $2.78(2.00-3.87)$ & $<0.001$ & $1.51(1.06-2.16)$ & 0.022 \\
\hline Higher & 1.00 & & 1.00 & \\
\hline \multicolumn{5}{|l|}{ Fathers' occupation } \\
\hline Currently not working & $1.13(0.77-1.67)$ & 0.539 & $0.95(0.63-1.42)$ & 0.793 \\
\hline Labour & $1.86(1.61-2.15)$ & $<0.001$ & $1.15(0.99-1.34)$ & 0.074 \\
\hline Service & $0.26(0.16-0.40)$ & $<0.001$ & $0.52(0.32-0.84)$ & 0.007 \\
\hline Business & 1.00 & & 1.00 & \\
\hline \multicolumn{5}{|l|}{ Mothers' working status } \\
\hline Currently not working & 1.00 & & 1.00 & \\
\hline Currently working & $1.16(1.01-1.32)$ & 0.034 & $0.95(0.82-1.10)$ & 0.506 \\
\hline \multicolumn{5}{|l|}{ Watching television } \\
\hline Not at all and do not know & $2.81(2.21-3.56)$ & $<0.001$ & $1.36(1.03-1.82)$ & 0.031 \\
\hline Less than once a week & $2.32(1.76-3.07)$ & $<0.001$ & $1.46(1.06-2.01)$ & 0.019 \\
\hline At least once a week & $1.03(0.80-1.31)$ & 0.841 & $1.14(0.86-1.51)$ & 0.349 \\
\hline all most everyday & 1.00 & & 1.00 & \\
\hline \multicolumn{5}{|l|}{ IPV } \\
\hline No & 1.00 & & 1.00 & \\
\hline Yes & $1.41(1.26-1.58)$ & $<0.001$ & $1.06(0.94-1.20)$ & 0.325 \\
\hline \multicolumn{5}{|l|}{ Wealth index } \\
\hline Poorer & $7.66(6.24-9.39)$ & $<0.001$ & $3.82(2.93-4.98)$ & $<0.001$ \\
\hline Poor & $4.72(3.82-5.84)$ & $<0.001$ & $2.74(2.11-3.57)$ & $<0.001$ \\
\hline Middle & $3.46(2.78-4.29)$ & $<0.001$ & $2.32(1.81-2.98)$ & $<0.001$ \\
\hline Richer & $1.98(1.57-2.50)$ & $<0.001$ & $1.59(1.24-2.03)$ & $<0.001$ \\
\hline Richest & 1.00 & & 1.00 & \\
\hline \multicolumn{5}{|l|}{ Place of residence } \\
\hline Urban & 1.00 & & 1.00 & \\
\hline Rural & $1.75(1.54-1.98)$ & $<0.001$ & $0.91(0.79-1.05)$ & 0.206 \\
\hline \multicolumn{5}{|l|}{ Birth cohorts } \\
\hline$<=2005$ & 1.00 & & 1.00 & \\
\hline $2006-2008$ & $0.64(0.55-0.74)$ & $<0.001$ & $0.79(0.67-0.94)$ & 0.008 \\
\hline $2009-2011$ & $0.52(0.45-0.60)$ & $<0.001$ & $0.64(0.54-0.76)$ & $<0.001$ \\
\hline $2012-2014$ & $0.37(0.31-0.45)$ & $<0.001$ & $0.51(0.41-0.63)$ & $<0.001$ \\
\hline
\end{tabular}




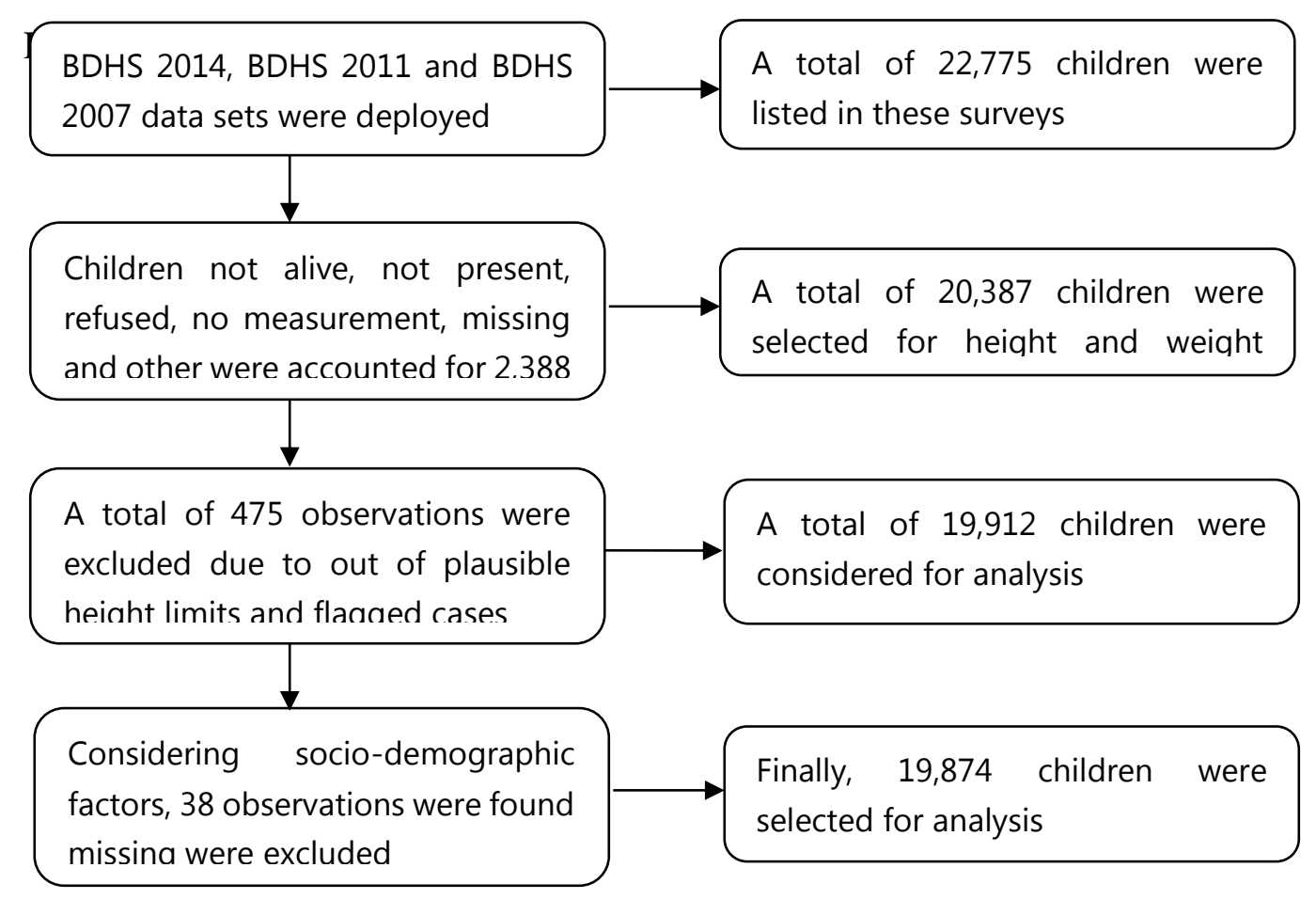

Figure. 1. Sample size selection 


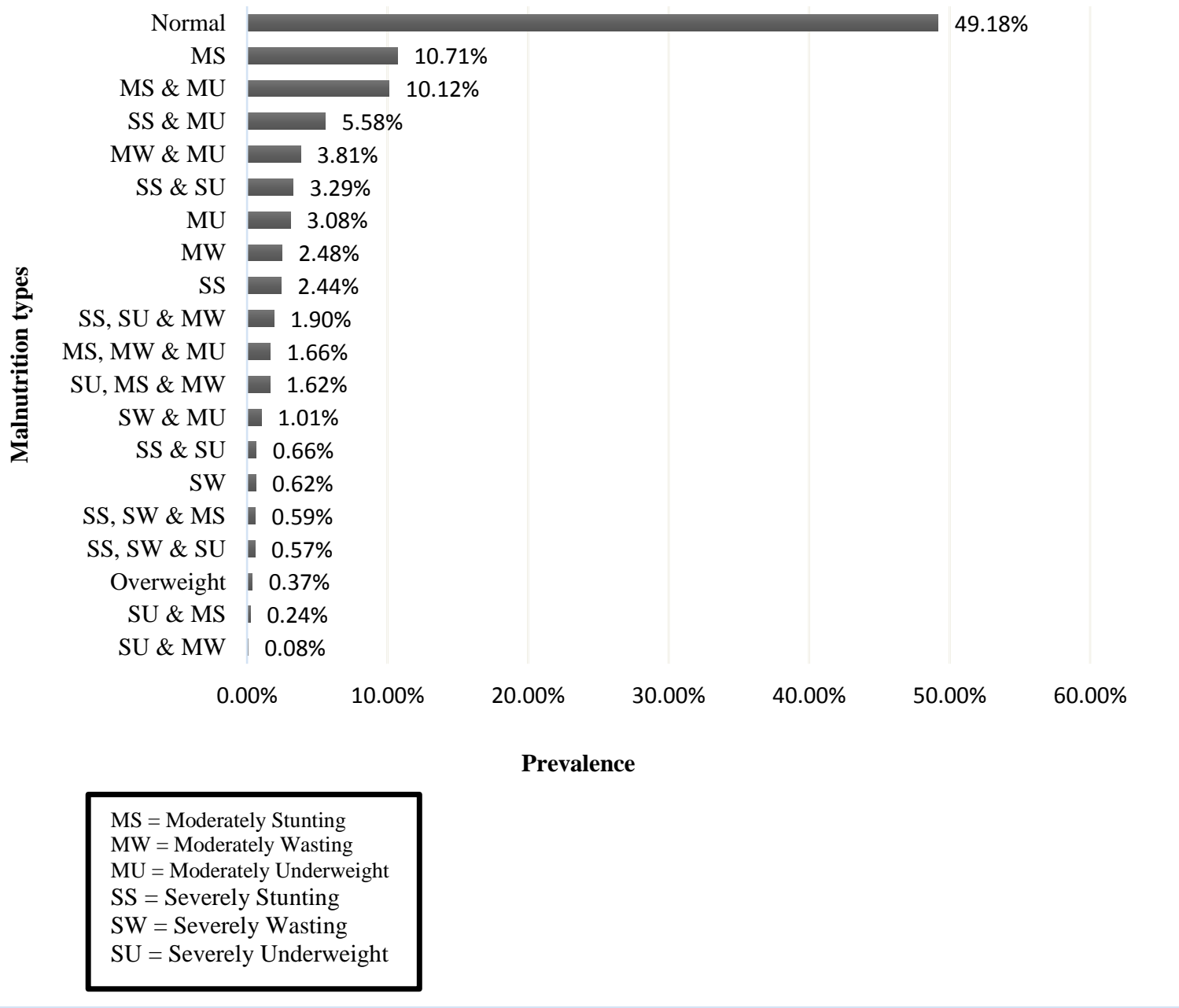

Figure. 2. Child malnutrition with single and multiple conditions (BDHS, 2014) 